\title{
Comparison of the Effectiveness of Various Deaeration Techniques
}

Owen S. Degenhardt ${ }^{1}$, Bonnie Waters' ${ }^{1}$, Anna Rebelo-Cameirao ${ }^{1}$, Annelene Meyer ${ }^{2}$, Heiko Brunner ${ }^{2}$, and Nicholas P. Toltt ${ }^{1,3}$

email:toltl_nick@lilly.com

\begin{abstract}
Many methods have been described for the deaeration of dissolution media, as required by the USP as well as worldwide regulatory agencies. The USP General Chapter Dissolution $<711>$ suggests heated vacuum filtration as one method of deaeration. This method of deaeration, when performed in our laboratories with $1 \mathrm{~L}$ of water produced media with $2.8 \mathrm{mg} / \mathrm{L}$ dissolved oxygen remaining. Helium sparging achieved lower levels of dissolved oxygen. Helium sparging produced media deaerated to the same level as the USP vacuum filtration technique if the media was sparged at a flow rate of $40 \mathrm{~mL} / \mathrm{s}$ for approximately 0.5 minutes per liter of media container volume. This recommendation is based on the fact that partially filled containers of dissolution media did not deaerate as efficiently as full ones. Other parameters such as media volume, gas flow rates, degassing time, analyst variability, and inlet filter pore size were all investigated to determine their effect on the deaeration process. The helium sparging deaeration technique was also effective for deoxygenating other aqueous dissolution buffers. Deaeration by heated vacuum filtration, Dissofill ${ }^{\mathrm{TM}}$ (automated heated filtration system), or by inert gas sparging prevented visible bubble formation during the dissolution experiment. However, monitoring of dissolved oxygen levels over the course of an entire dissolution experiment showed that more efficient deaeration of the dissolution media had no discernible effect on the final level of dissolved oxygen.
\end{abstract}

\section{Introduction}

The USP General Chapter $<711>$ states, "dissolved gases can cause bubbles to form, which may change the results of the test. In such cases, dissolved gases should be removed prior to testing"(1). Dissolved gases present in dissolution media can affect the results in a number of ways. The dissolved gas can significantly change the $\mathrm{pH}$ of an unbuffered solution, can interfere with the fluid-flow patterns through bubble formation, and can change the nature of the active ingredient and alter analytical values (2). Deaeration of dissolution media is therefore required to ensure that dissolved gases do not affect the results of a dissolution experiment. Deaeration will not prevent air from being trapped in pockets in the dissolution apparatus. Air pockets have been discussed elsewhere (2) and are beyond the scope of this work.

The USP recommends deaeration by a combination of heating and vacuum filtration followed by vigorous stirring of the medium under vacuum (1). To date, many authors have reported data for various deaeration techniques using vacuum filtration, heating, sonication, membrane filtration, and inert gas purging (3-7). Of these techniques, the least cumbersome and time-consuming method was the inert gas purge method (6), however, cost may be a consideration(3). Rolli and co-workers (8) have reported that the inert gas purge method was expensive due to lack of a good hardware design.

Once deaerated, the dissolution media must be transferred to a dissolution vessel and then stirred over the course of the dissolution run. One concern is the potential for the media to become reaerated during this time. Diebold and co-workers (7) showed that reaeration of dissolution media during media transfer is a concern as dissolved oxygen increased $275 \%$ in their study. Therefore, the determination of the effectiveness of deaeration techniques must also include a discussion of the potential for reaeration and the degree to which various factors impact the rate of reaeration.

The Dissolution $<711>$ chapter also states that other validated deaeration methods are acceptable. However, it is difficult to determine what is considered a validated method because to date, there is little data to show the effectiveness of the deaeration techniques. To this point, neither a desired level of dissolved gas nor acceptable validation standards for the methods are stated. This study was undertaken to evaluate various current deaeration practices and summarize the difference in effectiveness of each technique.

${ }^{3}$ Corresponding author:TOLTL_NICK@Lilly.com Tel.: 416-699-7323, FAX: 416-693-3752
'Eli Lilly Canada, Lilly Analytical Research Laboratories, 3650 Danforth Ave, Scarborough, Ontario, CANADA M1N 2E8 2Lilly Research Laboratories, Lilly Forschung $\mathrm{GmbH}$, Essener Strasse 93, D-22419 Hamburg, Germany 


\section{Experimental}

\section{Determination of Dissolved Oxygen Content}

The level of dissolved oxygen was measured using a YSI Model 55 Handheld Dissolved Oxygen meter. The dissolved oxygen probe is a polarographic sensor and as such consumes oxygen to take a reading. For a stable, accurate reading, media must flow past the probe. For readings in $1 \mathrm{~L}$ Erlenmeyer flasks, a magnetic stir bar and stir plate were used to achieve a uniform motion of media past the probe. In volumes larger than $1 \mathrm{~L}(6,24,48,92 \mathrm{~L})$ and for readings taken from dissolution vessels, the probe was manually swirled in the media until the reading stabilized. In all cases, the depth at which the reading was taken was approximately halfway between the bottom of the container and the surface of the media.

\section{Vacuum Filtration}

Purified Milli-Q water (1L) was heated to $41^{\circ} \mathrm{C}$ and stirred gently. The media was then vacuum-filtered through a $0.45 \mu \mathrm{m}$ filter (Gelman Sciences FP-450) and stirred vigorously under vacuum. A vacuum pump or water aspirator created the vacuum, and the vacuum pressure was monitored continuously with an in-line vacuum pressure meter (Trerice model 9187-08). Dissolved oxygen readings were taken after heating, after filtration, and after exposure to vacuum for 5, 10,15 and 20 minutes. Similar data was collected using automated heated filtration systems (Erweka's Dissofill and Distek's Dosaprep).

\section{Inert Gas Purge Technique}

The purge apparatus consisted of a tank of industrial grade helium and Tygon ${ }^{\circledR}$ tubing connected in series to a $150 \mathrm{~mm}$ flow meter (Omega, model \#FL-3405G), followed by a solvent inlet filter (Upchurch Scientific, $2 \mu$ m model A-222 or $10 \mu \mathrm{m}$ model A-302). The flow rate was determined by water displacement from an inverted graduated cylinder. Volumes of $1 \mathrm{~L}$ and $6 \mathrm{~L}$ were deaerated in adequately sized glass Erlenmeyer flasks while volumes of 24,48 , and $92 \mathrm{~L}$ were deaerated in an appropriately sized carboy.

\section{Results and Discussion}

\section{Comparison of Dissolved Oxygen Levels Using Both} Vacuum Filtration and Inert Gas Purging Techniques

The manual vacuum filtration technique outlined in USP Dissolution General Chapter < 711 > was examined in order to set a target level of dissolved oxygen remaining in the media after deaeration. Once the target level was established, other techniques could then be assessed against the USP method. Predictably, the amount of oxygen removed by vacuum filtration deaeration was affected by the vacuum pressure used and by the length of time the media was stirred. For our laboratory set-up, achievable

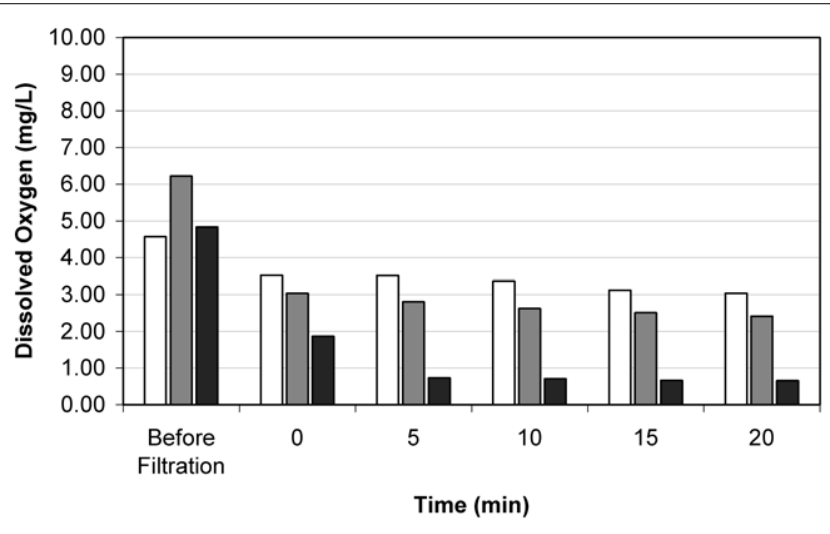

Figure 1: Levels of dissolved oxygen remaining at manual vacuum filtration at pressures of (- $\square-)-30 \mathrm{kPa},(-\square-)-60 \mathrm{kPa}$, and (-口-) $-90 \mathrm{kPa}$.

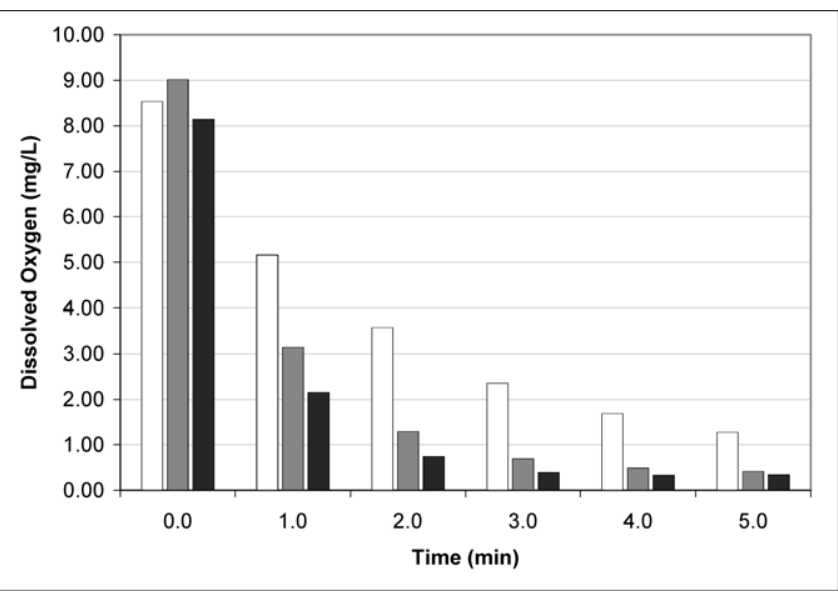

Figure 2: Levels of dissolved oxygen remaining after helium sparging at gas

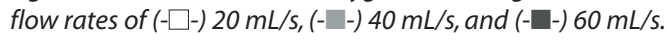

vacuum ranged from $-90 \mathrm{kPa}$ to $-30 \mathrm{kPa}$. In order to optimize the vacuum pressure needed to achieve deaeration in a reasonable amount of time, the rate of deaeration at various pressures $(-90 \mathrm{kPa},-60 \mathrm{kPa}$, and $-30 \mathrm{kPa}$ ) were investigated (Figure 1). More rapid deaeration occurred under higher vacuum conditions. The achievable level of deaeration using this technique for $1 \mathrm{~L}$ of media in an Erlenmeyer flask was $2.8 \mathrm{mg} / \mathrm{L}$ dissolved oxygen and this value was reproducible from run to run and from analyst to analyst. Considering reasonable vacuum conditions and time constraints, this target concentration of dissolved oxygen was achieved after 5 minutes of stirring at a pressure of about $-60 \mathrm{kPa}$ and a temperature of $41.7^{\circ} \mathrm{C}$. The automated Dissofill unit deaerated media to an average concentration of $3.4 \mathrm{mg} / \mathrm{L}$ oxygen (or approximately $50 \%$ of saturation) at $37^{\circ} \mathrm{C}$.

Similarly, deaeration of media by helium sparging was investigated to determine this technique's ability to 

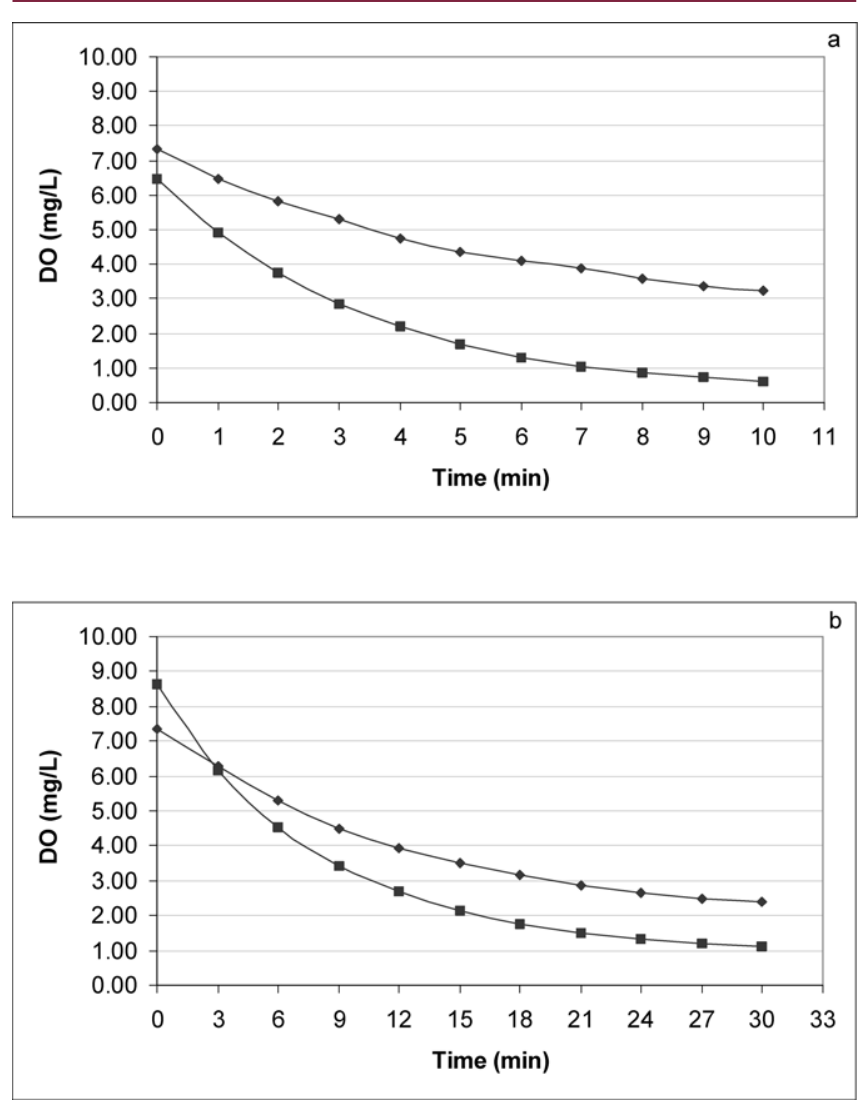

Figure 3a: Levels of dissolved oxygen remaining after helium sparging at gas flow rates $40 \mathrm{~mL} / \mathrm{s}$ of $6 \mathrm{~L}$ of water in (- - -) $48 \mathrm{~L}$ carboy and a (-口-) $6 \mathrm{~L}$ glass Erlenmeyer flask.

Figure 3b: Levels of dissolved oxygen remaining after helium sparging at gas flow rates $40 \mathrm{~mL} / \mathrm{s}$ of $24 \mathrm{~L}$ of water in (-) $48 \mathrm{~L}$ carboy and a (--) $24 \mathrm{~L}$ carboy.

achieve dissolved oxygen levels similar to that afforded by the vacuum filtration method. The deaeration rate as a function of helium flow rate was determined at flow rates of 20,40 and $60 \mathrm{~mL} / \mathrm{s}$ (Figure 2) through $1 \mathrm{~L}$ of water. The rate of deaeration by helium sparge was dependent upon the flow rate of the helium and sparging duration. A much lower concentration of dissolved oxygen can be achieved in a shorter time by helium sparging than by the vacuum filtration technique. Even at the lowest flow rate used (20 $\mathrm{mL} / \mathrm{s}$ ) only about 2.5 minutes was required to obtain dissolved oxygen levels comparable to those achieved with vacuum filtration for $1 \mathrm{~L}$ of water.

\section{Inert Gas Purging of Partially Filled Dissolution Media Carboys}

To this point, the dissolved oxygen levels achievable during deaeration have been based on helium sparging of full dissolution media containers. The deaeration efficiency of partially filled containers was investigated to examine the effectiveness of the helium sparge method under these conditions. To illustrate this, $6 \mathrm{~L}$ of water was placed in a $6 \mathrm{~L}$ glass Erlenmeyer flask and in a 48L carboy and the volume of dissolved oxygen present was monitored (Figure 3a). Deaeration in the $6 \mathrm{~L}$ flask was far more efficient than deaeration observed for the same amount of liquid in the $48 \mathrm{~L}$ carboy. Even after 10 minutes of helium sparging,
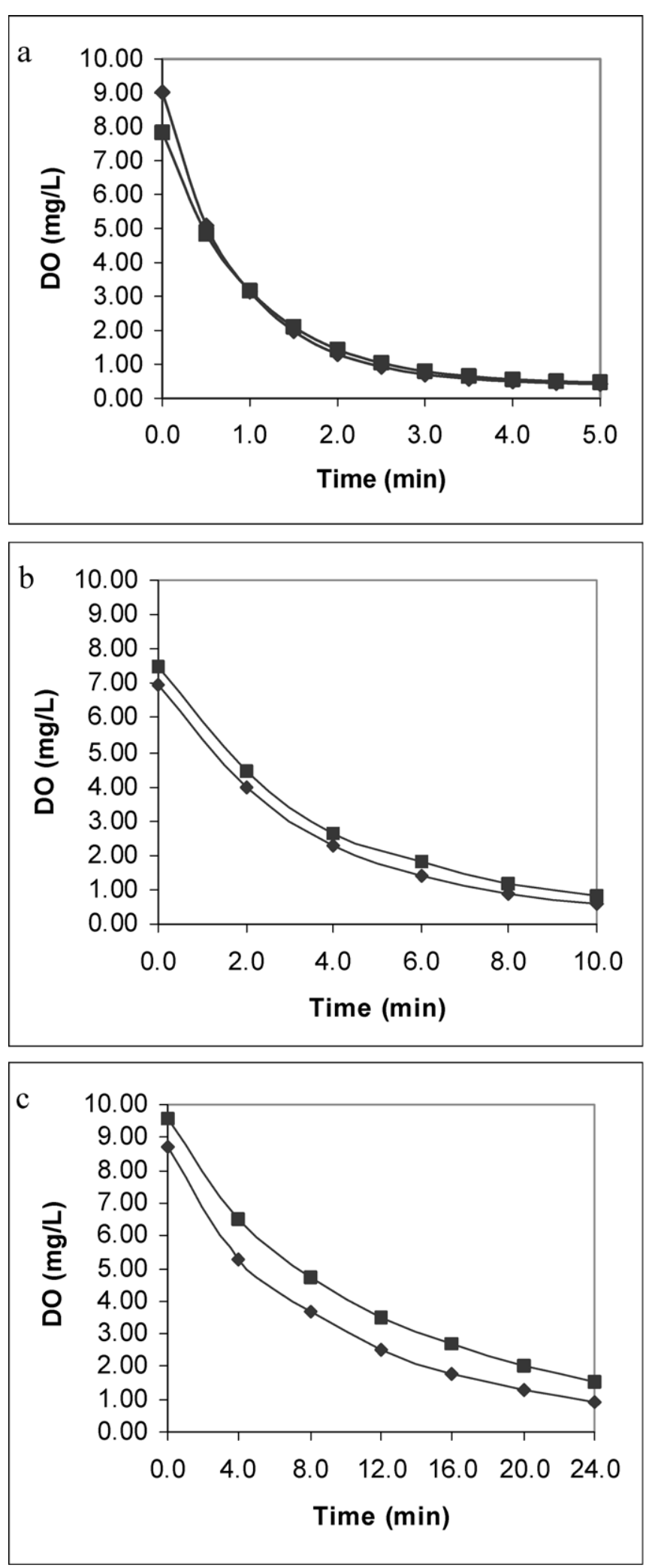

Figure 4: Deaeration by helium sparging with (-口-) $10 \mu \mathrm{m}$ and (- - -) $2 \mu \mathrm{m}$ pore-size filters and media volumes of a) $1 L, b) 6 L$, and c) $24 L$.

the relatively small volume of dissolution media in the carboy could not attain the USP target level of dissolved oxygen $(2.8 \mathrm{mg} / \mathrm{L})$. Similarly, $24 \mathrm{~L}$ of water was placed in a $24 \mathrm{~L}$ and a $48 \mathrm{~L}$ carboy and the volume of dissolved oxygen present was monitored (Figure 3b). The deaeration of $24 \mathrm{~L}$ of dissolution media was less efficient in the 48L carboy, 
requiring $\sim 24$ minutes to achieve the USP target. Therefore, the recommended inert gas purging times are based on the total volume of the media container itself and not the volume of media remaining in the container.

\section{Effect of Inlet Filter Pore Size and Media Volume on Helium Sparge Deaeration Efficiency}

The inert gas purge set-up involves helium flowing into the media through an inlet filter. The size of the pores of the filter may impact the flow properties of the helium and in turn influence the rate of deaeration. The effect of filter pore size on deaeration by helium sparge was investigated using two solvent inlet filters ( $2 \mu \mathrm{m}$ and $10 \mu \mathrm{m}$ ). There was no discernible difference in the rate of deaeration (Figure $4 a)$ for 1-L volumes. Only slight differences in deaeration effectiveness were observed at larger volumes $(6 \mathrm{~L}$ and $24 \mathrm{~L}$ ), and this is mostly due to the start point of the deaeration process (Figures $4 b, c)$. The rate of deaeration in the different volumes is equivalent; therefore the pore size of the filter has no effect on the outcome.

Vacuum filtration becomes less practical as dissolution media volume increases. The apparatus allows only for preparation of small volumes (1-5L) that require time to heat the media and to stir the media vigorously under vacuum. At functional volumes of dissolution media (692L), helium sparging achieved lower concentrations of dissolved oxygen as compared to the target of $2.8 \mathrm{mg} / \mathrm{L}$ achieved by vacuum filtration (Figure 5 ). The lowest attainable concentration of dissolved oxygen increased as the volume being deaerated increased. Generally, it was found that sparging approximately 0.5 minutes at a flow rate of $40 \mathrm{~mL} / \mathrm{s}$ per liter of media container volume was required to meet the target dissolved oxygen concentration of 2.8 $\mathrm{mg} / \mathrm{L}$ achieved by the vacuum filtration method.

\section{Comparison of the Rate of Re-aeration Prior to and During a Dissolution Run}

Dissolved oxygen measurements were measured after the transfer of the media to the dissolution vessel, after equilibration to $37^{\circ} \mathrm{C}$, and after the dissolution run, with paddles at $50 \mathrm{rpm}$ for 45 minutes (Figure 6), in order to quantitate the re-aeration. The concentration of dissolved oxygen after a 45-minute dissolution run was similar for media deaerated by vacuum filtration (manual or automated), and by helium sparging. None of the three deaerated media re-aerated to the concentration observed prior to deaeration and none of the deaerated media showed bubble formation over the course of the dissolution test. In dissolution experiments performed with non-deaerated media, bubbles were observed on the paddle, shaft of the paddle, the capsule, and the capsule sinker. Occasionally, bubbles formed on the bottom of the vessel. In comparison to these control experiments, experiments performed with deaerated media were virtually bubble-free.

Although the helium purge technique affords a more efficient route for deaeration than either the manual vacuum or automated techniques, the concentration of dissolved

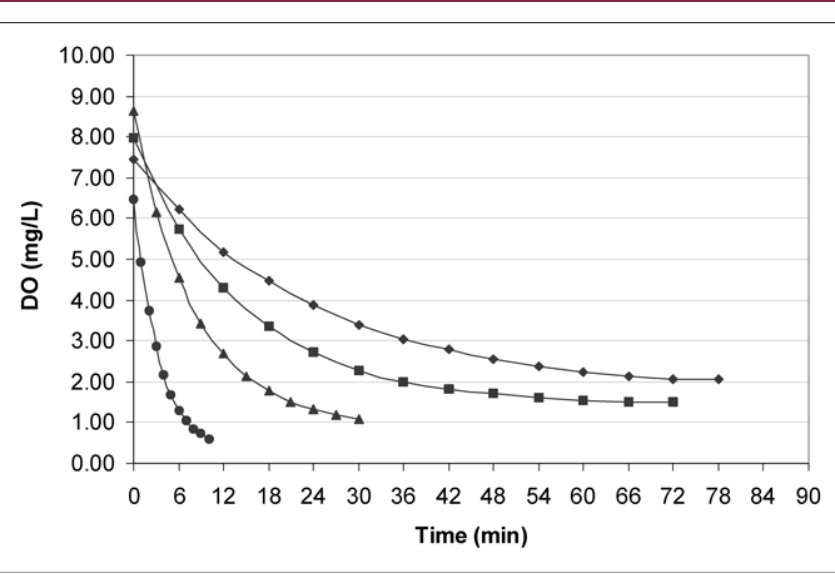

Figure 5: Deaeration by helium sparging at $40 \mathrm{~mL} / \mathrm{s}$ with media volumes of

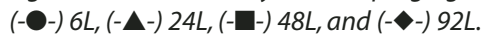

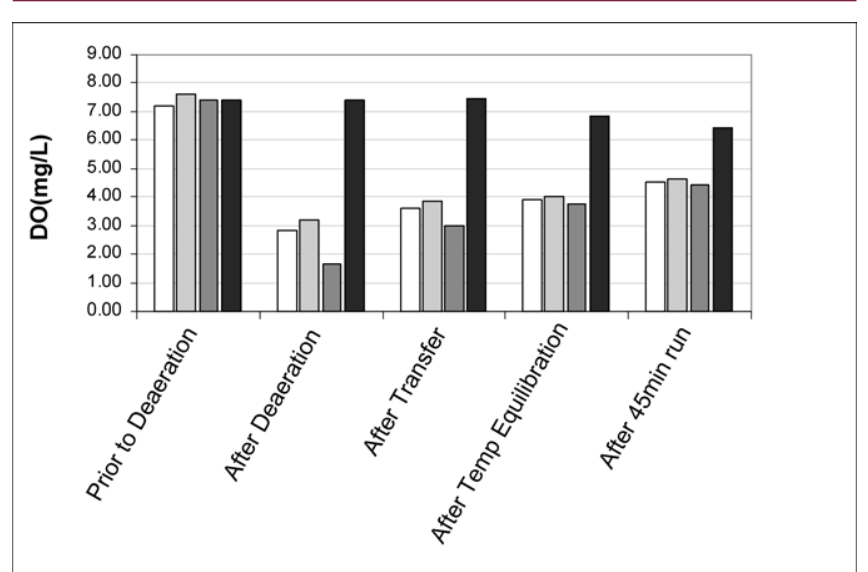

Figure 6: Levels of dissolved oxygen remaining after various stages of a dissolution run using (- $\square$-) Manual vacuum filtration, (- -) Dissofill automated filtration (-_-) Helium sparging, and (-口-) Non-deaerated media.

oxygen at the end of the dissolution run is independent of the deaeration technique used.

Re-aeration due to transfer of media to the dissolution vessel was highly variable because the process consisted of two steps for manual deaeration methods: transfer to a measuring vessel followed by transfer from the measuring vessel to the dissolution vessel. In addition, each transfer may be affected by several factors, including rate of pouring, method of pouring (middle of the vessel or down the side), pouring height, and the difference between the partial pressure of the oxygen in the air and in the deaerated medium. It should be noted that the automated vacuum filtration technique allows the media to be directly dispensed into a dissolution vessel. However, for this experiment, the contents of the dissolution vessel containing the Dissofill-deaerated media was transferred to a graduated cylinder prior to re-dispensing back into the dissolution vessel to compare this technique to the other deaeration methods requiring two transfer steps.

The impact of analyst practices on dissolved oxygen levels in deaerated media was also investigated. A carboy containing $24 \mathrm{~L}$ of water was deaerated by helium sparging to a dissolved oxygen level of $2.6 \mathrm{mg} / \mathrm{L}$. In an attempt to analyze the effect of a best practice scenario, the water was dispensed into a graduated cylinder and all efforts were made to eliminate agitation of the media. Nevertheless, re-aeration to 4.0 
$\mathrm{mg} / \mathrm{L}$ of dissolved oxygen was observed. The same $1 \mathrm{~L}$ of media was then gently poured from the graduated cylinder down the side of the dissolution vessel resulting in minimal additional re-aeration, reaching a dissolved oxygen level of $4.2 \mathrm{mg} / \mathrm{L}$. Next, a worst practice scenario was mimicked through vigorous agitation and rapid dispensing of the media into the graduated cylinder. This technique afforded dissolved oxygen levels of $4.7 \mathrm{mg} / \mathrm{L}$. In addition, pouring the dissolution media from the graduated cylinder into the center of the dissolution vessel, again with vigorous mixing, resulted in a final dissolved oxygen level of $5.2 \mathrm{mg} / \mathrm{L}$. Therefore, it is important that when handling and transferring deaerated media, care is taken not to over-agitate the media.

Deaeration results obtained in a different laboratory (9) were similar to those observed in our lab. After manual vacuum filtration of $5 \mathrm{~L}$ of media, the concentration of dissolved oxygen, measured after the media was transferred to a dissolution vessel, was $4.4 \mathrm{mg} / \mathrm{L}$. Increased variability of the results was observed with deaeration by manual vacuum filtration. The use of a Dosaprep system showed that dissolved oxygen concentrations of $3.8 \mathrm{mg} / \mathrm{L}$ were achievable. The final levels of dissolved oxygen (4.4$4.8 \mathrm{mg} / \mathrm{L}$ ) after a 30-minute dissolution run were independent of the analyst performing the experiment. The concentration of dissolved oxygen after a dissolution experiment is about $4.6 \mathrm{mg} / \mathrm{L}$, despite the difference in deaeration technique, apparatus, equipment, and analyst.

\section{Investigation into the Rate of Re-aeration of Unused Dissolution Media}

The overnight re-aeration of deaerated media was investigated and offers insight as to the re-aeration of unused portions of previously deaerated media. One liter of water was deaerated by each technique - manual, automated filtration, or helium sparge. The initial concentrations of dissolved oxygen were $2.9,3.4$, and $0.8 \mathrm{mg} / \mathrm{L}$ respectively. The level of dissolved oxygen in each of the media portions after standing for 16 hours had increased by 2.3, 2.6 and $2.0 \mathrm{mg} / \mathrm{L}$ of dissolved oxygen, respectively. It is apparent that for unagitated, sealed media, the level of dissolved oxygen increases at about the same rate irrespective of the initial dissolved oxygen level (Figure 7a). Similarly, the effect of overnight re-aeration was examined as a function of media volume. At all volumes (6-92L), deaerated dissolution media (helium purge technique), sealed to the atmosphere and left unagitated overnight showed some increase in dissolved oxygen (Figure 7b). Although re-aeration back to the original levels of dissolved oxygen did not occur, it is recommended that media be deaerated once a day.

\section{Effect of pH on the Deaeration and Rate of Re-aera- tion of Dissolution Media}

To this point, water was used as representative media for the deaeration/re-aeration process. Deaeration by helium sparge was examined in $0.1 \mathrm{~N} \mathrm{HCl}$ and $\mathrm{pH} 6.8$ phosphate buffer. It was determined that deaeration of $6 \mathrm{~L}$ of these
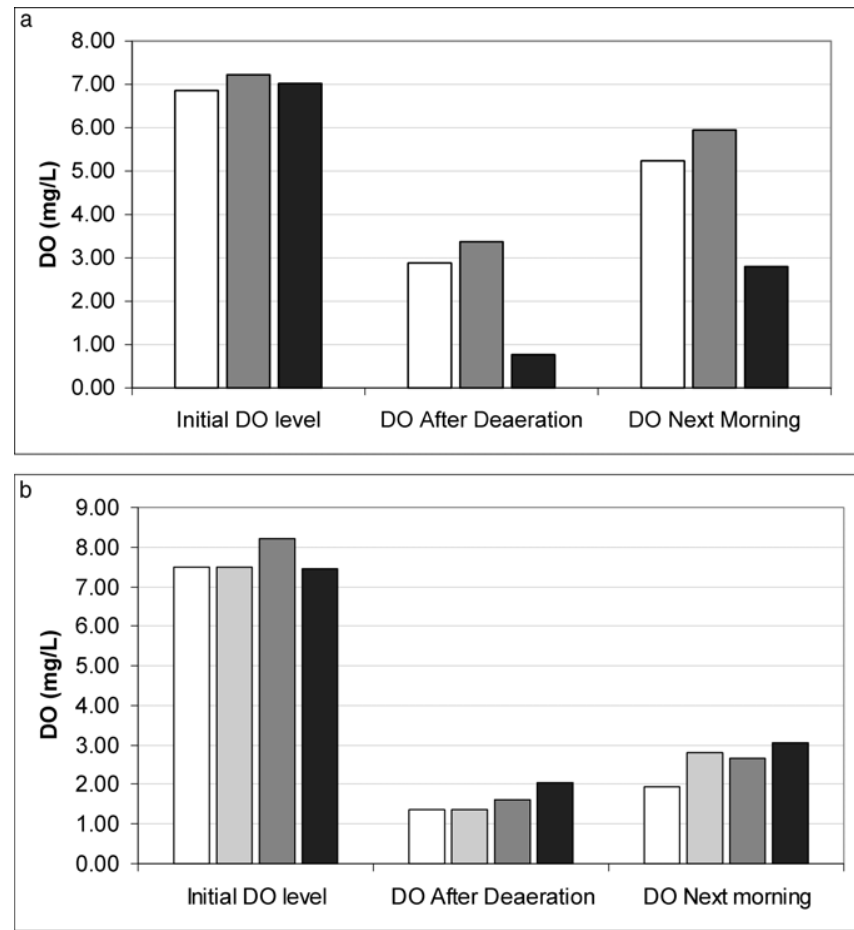

Figure 7a: Rates of re-aeration of $1 L$ sealed, un-agitated media using (- $\square-)$ Manual vacuum filtration, (---) Dissofill automated filtration, and (-口-) Helium sparging.

Figure $7 b$ : Rates of re-aeration of un-agitated media at volumes of (- $\square-$-) $6 L$, (--) $24 \mathrm{~L}(-\mathbf{-}-)$ 48L, and (-口-) $92 \mathrm{~L}$.

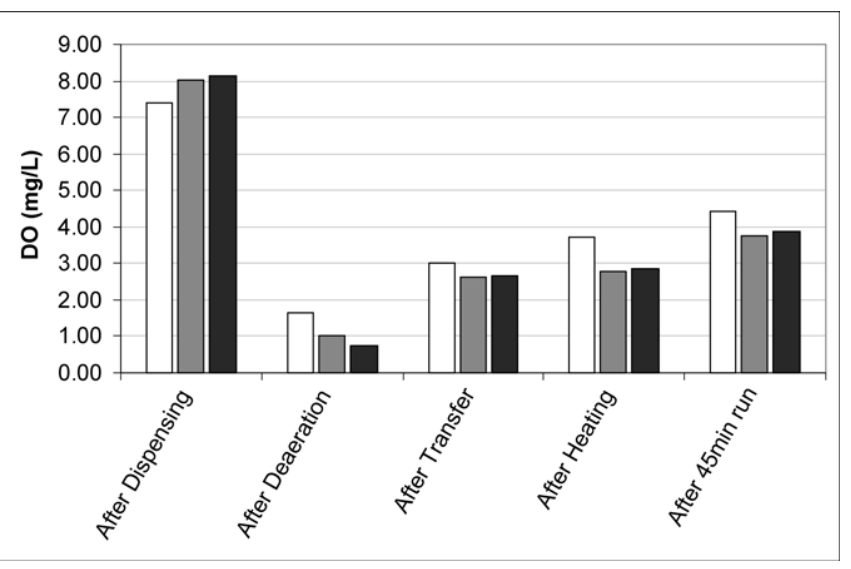

Figure 8: Levels of dissolved oxygen remaining after various stages of a dissolution run using (- $\square$-) Water, (---) $0.1 \mathrm{~N} \mathrm{HCl}$, and (--) Phosphate buffer (pH 6.8).

two media was more efficient than deaeration of water. After transferring the media to dissolution vessels and conducting a dissolution run, we found the level of dissolved oxygen present at the end of the experiment was similar in all 3 media (Figure 8). These findings confirm that the helium sparge method of deaeration successfully deaerates media containing different additives and at different $\mathrm{pH}$ levels.

\section{Conclusion}

The vacuum filtration method of deaeration, as outlined in the USP General Chapter on Dissolution $<711>$, reduced the concentration of dissolved oxygen in water to 2.8 $\mathrm{mg} / \mathrm{L}$. The automated Dissofill method afforded compa- 
rable levels of dissolved oxygen and provided increased efficiency when deaerating larger volumes of dissolution media. The helium sparge method was also evaluated, and it was found to be the most effective and efficient of the three. It is recommended that media be sparged for roughly half a minute per liter of container volume at a helium flow rate of $40 \mathrm{~mL} / \mathrm{s}$, using an inlet filter pore size between 2 and $10 \mu \mathrm{m}$. Helium sparge is recommended as the method of choice for aqueous dissolution media volumes from $6 \mathrm{~L}$ to $92 \mathrm{~L}$.

Deaeration, regardless of the deaeration method employed, prevented the formation of visible bubbles during a dissolution run. The initial concentration of dissolved oxygen present in the media did not affect the concentration of oxygen present at the end of the dissolution experiment. Excessive deaeration of dissolution media only serves to increase the rate of re-aeration during the course of media transfer and 30-45 minutes of paddle agitation. This was demonstrated in $0.1 \mathrm{~N} \mathrm{HCl}$ and pH 6.8 phosphate buffer in addition to purified water. Other laboratories, using similar equipment and conditions, have reported similar results.

\section{Acknowledgements}

The authors would like to thank James Bucko for insightful discussions throughout the course of this work. The authors would also like to acknowledge the participation of Y.C. Lee during the early part of this work, and Paul Culbert for insightful discussions and his review of the manuscript.

\section{References}

1. USP 25, January 1, 2002.

2. Hanson, WA, "Handbook of Dissolution Testing." Pharmaceutical Technology Publications, Springfield, Oregon, 1982.

3. Griffith, M.F., Curley, T.E., Martin, GP, “Considerations in Choosing a Deaeration Technique for Dissolution Media." Dissolution Technologies, 4 (1, February), 16-17, 1997.

4. Qureshi, S.A., McGilveray, I.J., "Impact of Different Deaeration Methods on the USP Dissolution Apparatus Suitability Test Criteria." Pharmacopeial Forum, 20, 8565-8566, 1994.

5. Rohrs, BR, Steiner, DJ, “Deaeration Techniques for Dissolution Media." Dissolution Technologies, 2 (2, Winter), 7-8, 1995.

6. Moore, T.W., “Dissolution Testing: A fast, Efficient Procedure for Degassing Dissolution Medium." Dissolution Technologies, 3 (2, May), 3-5, 1996.

7. Diebold, S.M., Dressman, J.B., "Dissolved Oxygen as a Measure for De- and Reaeration of Aqueous Media for Dissolution Testing." Dissolution Technologies, 5 (3, August), 13-16, 1998

8. Rolli, R., Fiechter, A., Hengst, R., "In-Situ Deaeration of Dissolution Media Through a Hollow Shaft System." Dissolution Technologies, 7 (2, May), 20-22, 2000.

9. Experiments performed at the Lilly Research Laboratories, Lilly Forschung GmbH, Essener Strasse 93, D-22419 Hamburg, Germany 